Bulletin UASVM Food Science and Technology 70(2)/2013, 74-82

ISSN-L 2344-2344; Print ISSN 2344-2344; Electronic ISSN 2344-5300

\title{
Bioactive Labels for Fresh Fruits and Vegetables
}

\author{
Liana NĂSUI, Dan VODNAR*, Carmen SOCACIU \\ University of Agricultural Sciences and Veterinary Medicine, Food Science and Tehcnology \\ Department, Mănăştur Nr. 3-5, Cluj-Napoca, 400372 Romania; \\ vodnar_dan@yahoo.co.uk
}

\begin{abstract}
Pesticide residues and microbial load on the surface of fresh fruits and vegetables becomes a major concern due to the safety and quality of these products for consumer.In order to minimize these risk factors (pesticide residues and microbial load), were achieved labels for fruits and vegetables that are consumed with shell which disintegrates under the influence of water jet and thus reduce the amount of these contaminants. Were elaborated labels based on polymer (chitosan) at a concentration of $2 \%$, which incorporate bioactive compounds from green tea with potential decontaminant of the peel of these products. Green tea extract was obtained by infusing $1 \mathrm{~g}$ of dried green tea in $100 \mathrm{ml}$ water at $80^{\circ} \mathrm{C}$ for 10 minutes. The extract was filtered and then mixed with $2 \mathrm{~g}$ chitosan acidified with $0.7 \%$ glacial acetic acid and dilute to the mark with distilled water. Were identified bioactive compounds from green tea, using UV-VIS and HPLC. Then were elaborated the labels. These tags were used on pepper, tomato, apple and nectarine. Were quantified the microbial load and the pesticide residues on their surface unwashed, washed only with water and were monitored the influence of labels on these factors. Identified pesticides were mefenoxan and thiamethoxam, which were quantified by HPLC. In what it concerns the influence, were founded the absence of germs at pepper and a significant decrease at the other. In terms of the potential of reducing pesticide, the experimental results have indicated that the label can prove its effectiveness.
\end{abstract}

Keywords: HPLC, bioactive lables, green tea, safety

\section{INTRODUCTION}

From a nutritional perspective, fresh fruits and vegetables, stored under appropriate conditions, are a veritable source of vitamins and minerals, bringing benefits to all systems in the body. A current problem with a large resonance for these products consists in the microbial load and in the pesticide residues on their surface (A. Zander, M. Bunning, 2010).

Microbiology of fresh horticultural products is heterogeneous and depends on the variety, size, anatomical structure, degree of ripeness, harvesting, handling, transport, storage, and also vary in terms of quantity, depending on these factors (Apostu, 2009).

Their resistance to various microorganisms is closely correlated with a number of features: anatomical structure of the products, protective substances such as waxes, antimicrobial substances: organic acids, essential oils- fitoncide substances, formation of chemical compounds in place where the infection occurred (Apostu, 2009).

Fresh fruits and vegetables can also be a source of noxious toxic substance pesticides. Pesticides constitute a very important group of chemical compounds, which have to be controlled due to their high toxicity and their widespread use in agricultural practices for field and post-harvest protection (Krol et al., 2000).

A large amount of pesticide is sprayed onto the outside of the product, and it can be removed by peeling (citrus, cucumbers, melons, watermelon, etc.), but the problem continues to those fruits and vegetables that this should not be made (peppers, tomatoes, apples, 
nectarines, pears, plums, etc..). Peel fruit and vegetables is valuable nutritionally, bringing a number of benefits to the human body (Devgan K., 2012).

Once these substances are applied to crops, they may be washed out by rain, they can be degraded by volatilization, by microorganisms or by photolysis. In addition they can be absorbed by the surface of the plants (cuticle waxes and root surfaces) and could enter into the transmission of the plant (systemic circulation) or allowed to remain at their surfaces (Keikothaile et al., 2010).

Until now were not created labels based only on natural compounds. The main disadvantage of products that have been created so far for this purpose is given by the class of chlorates which can remain in small amounts on the surface of the fruit and vegetables and after washing, can be ingested by the consumer.

The aim of this work was to create labels based by polymer (chitosan), which incorporate bioactive compounds from green tea with potential decontaminantion of the peel of these products.

\section{MATERIALS AND METHODS}

\section{Chemical characterization}

The extract of green tea was prepared in advance by the infusion method to reveal the presence of phenolic acids.

In the first part of the study were identified the bioactive compounds from green tea using Able Jasco Spectrophotometer with spectral range 200-1100 nm.

Green tea catechins were identified using HPLC Agilent $1200 \mathrm{UV}-\mathrm{Vis}$ detector. The column used was a Supelcosil LC 18 and the detection was set at $280 \mathrm{~nm}$. The mobile phase consisted on: Solvent A: methanol / ac. glacial acetic acid / water in a ratio of 10/02/88 (v / v)

Solvent B: methanol / ac. glacial acetic acid / water ratio of 90/3/7.

Procedure: HPLC separation of phenolic compounds in tea methanol extracts was performed in a HPLC Agilent $1200 \mathrm{UV}$-Vis detector. For each injection were used $20 \mu \mathrm{l}$ extract and column temperature was set at $25^{\circ} \mathrm{C}$.

In what it concerns the potential of biodegradable labels to reduce pesticides on the surface of fruits and vegetables the European standardization EN 12393:2003 establishes general considerations for determining pesticide residues in non-fatty foods.

We used the following: Analytical balance, precision \pm 0.1 , Filter paper, HPLC Agilent 1200 UV-Vis detector, column Supelcosil LC 18, wavelength $280 \mathrm{~nm}$, Solvent A sol. $2 \mathrm{mM}$ ammonium acetate / 0.4\% acetic acid Solvent B - Soil. Acetonitrile / methanol, 3/1.

\section{Extraction of green tea phenols}

The method used involved repeated and continuous extraction of the material to be analyzed, with a limited volume of methanol. Procedure: The test sample is weighed $1 \mathrm{~g}$ analytical balance and add $5 \mathrm{ml}$ solvent. Extraction was carried out with methanol, after 30 min of continuous agitation. And then allow extracting 24 hours in the dark at room temperature. The obtained extract was filtered through filter paper and then by HPLC 0.45 micron filter.

\section{Determination of phenolic acids from green tea by UV-VIS spectrophotometer}

Procedure: Were used Jasco 530 UV-Vis Spectrophotometer. UV-Vis spectrum was recorded for the extract prepared to reveal the presence of phenolic acids. Control unit built: 
acquisition spectral measurements Abs / T\%, quantitative determination of calibration curves, kinetic measurements, print results and graphs by connecting a printer.

\section{Fruit and vegetable lables formulation}

Technical balance of precision \pm 0.1 , thermoregulation water bath at $80^{\circ} \mathrm{C}$, filter paper, pipettes $0.5,1,2 \mathrm{ml}$, tubes with $50 \mathrm{ml}$ volumes, camera trituration, Petri dishes with a diameter of $9-10 \mathrm{~cm}$, sterilizer $115^{\circ} \mathrm{C}, 15 \mathrm{~min}$, drying stove, spatulas.

We used the following procedure: Following the preparation of $100 \mathrm{ml}$ of the product were performed 25 labels with a diameter of $4.5 \mathrm{~cm}$. Plant extracts (green tea) were obtained by infusing $2 \mathrm{~g}$ of dried plant into $100 \mathrm{ml}$ of water at $80^{\circ} \mathrm{C}$ for 10 minutes. The extract was filtered and then mixed with $2 \mathrm{~g}$ chitosan and brought to the mark with distilled water. The $2 \mathrm{~g}$ of polymer are required in prior acidification with $0.7 \mathrm{ml}$ of glacial acetic acid, because it is not soluble in neutral or basic solutions. The mixture was sterilized at $100^{\circ} \mathrm{C}$ for 7 minutes, then was poured into $4.5 \mathrm{~cm}$ diameter plate. The plates were exposed to the process of dehydration in drying stove at $30^{\circ} \mathrm{C}$ for 6 hours. After the drying, the discs formed were detached from the surface of the Petri dishes after which they may be cut, finished and can be printed with the inks obtained from natural pigments. Thus made, they were stored at $25^{\circ} \mathrm{C}$ and humidity of $40 \%$ until the moment of their use.

\section{Microbiological determination}

The total number of germs (NTG) is a major health microbiological indicator and it provides data on the general investigational product contamination (Apostu S., Rotar M. Ancuța, 2009).

Were used technical balance accuracy \pm 0.1 , trituration device, drying stove, water bath set at $50^{\circ} \mathrm{C}$. Petri dishes with a diameter of 9-10 cm, $1.2 \mathrm{ml}$ pipettes, tubes of 160/16 $\mathrm{mm}$, agar nutrient, sanitation wipes and were established the bacterial load of fruit and vegetables by determining the total aerobic bacteria that grow at $37^{\circ} \mathrm{C}$. The surface of fruit and vegetable was cleaned with sterile swabs sanitation that are inserted into tubes with $90 \mathrm{ml}$ saline and triturated. From the homogenate made was taked $2 \mathrm{ml}$ with a graduated pipette and dispensed $1 \mathrm{ml}$ in 2 Petri dishes. In each plate was put 14-16 ml of medium, melted and cooled to $50{ }^{\circ} \mathrm{C}$ (water bath kept). After distribution of agar per plate were carried out slightly moves for incorporation and mixing with the inoculum. Petri plates were placed on a perfectly flat surface with the cover ajar until the medium is solid, and the surface is no longer drops of condensation. Plates was made with the lid down and placed in the drying stove for incubation, followed by a period of 24-48 hours to read the result. This was determined by counting the colonies from the plates in which micro-organisms have been developed.

\section{RESULTS AND DISCUSSIONS}

\section{Identification of bioactive compounds in green tea}

1. Determination of phenolic acids from green tea by UV-VIS spectrophotometer 


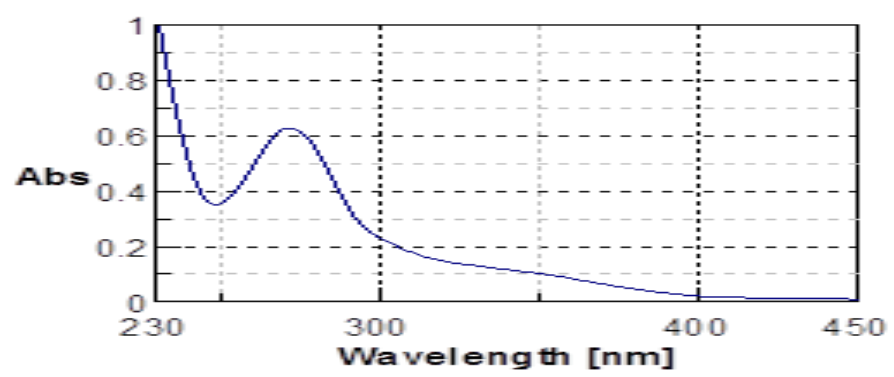

Fig. 1. Spectophotometric footprint of green tea (phenolic acids $-280 \mathrm{~nm}$ )

It is observed the characteristic spectrum of this class of biologically active compounds (phenolic acids) with a maximum absorption at $280 \mathrm{~nm}$ wavelength (Fig. 1).

Green tea composition is very similar to that of the fresh leaf except for a few enzymatically catalyzed changes which occur extremely rapidly following plucking. New volatile substances are produced during the drying stage. Fresh tea leaf is unusually rich in the flavanol group of polyphenols known as catechins which may constitute up to $30 \%$ of the dry leaf weight. Other polyphenols include flavonols and their glycosides, and depsides such as chlorogenic acid, coumarylquinic acid, and one unique to tea, theogallin (3-galloylquinic acid). Caffeine is present at an average level of 3\% along with very small amounts of the other common methylxanthines, theobromine and theophylline. The amino acid theanine (5nethylglutamine) is also unique to tea. (Graham N. H., 1992).

Numerous studies have indicated that epigallocatechin gallate, epigallocatechin, and theanine were detrmined as the major catechins and free amino acid, respectively (Kim K-Y. et al., 2009 ). Also, in 1998 Alschuler L. and in 2006 Zafery T. Nurulain were treated in their studies these compounds.

2. Quantification of phenolic acids from green tea by HPLC

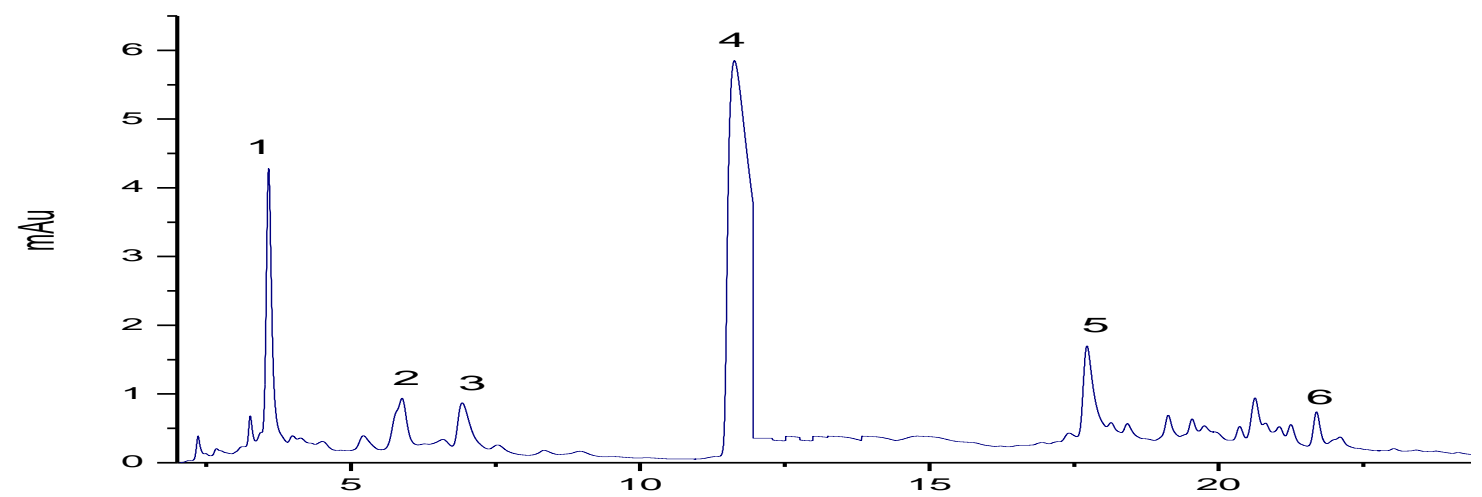

Fig 2. Chromatogram of green tea polyphenols

Peak number shown: 1, EGC (epigallocatechin), $\mathrm{t}_{\mathrm{R}}=3.6 \mathrm{~min} ; 2, \mathrm{C}$ (catechin), $\mathrm{t}_{\mathrm{R}}=5.81 \mathrm{~min}$; 3, EC (epicatechin), $t_{R}=6.99 \mathrm{~min} ; 4$, EGCG (epigallocatechingallate), $t_{R}=11.71 \mathrm{~min} ; 5, \mathrm{CAF}$ (caffeic acid), $t_{R}=17.73 \mathrm{~min} ; 6$, ECG (epicatechingallate), $t_{R}=21.67 \mathrm{~min}$.

Identification of phenolic compounds, at green tea (Fig. 2), was done by comparing the retention times of standards with retention times of samples. 
Tab. 1

The concentration of catechins and caffeine in green tea extract

\begin{tabular}{|c|c|c|}
\hline Signal & Compound & $\begin{array}{r}\text { GT } 2 \% \\
\mathrm{mg} / \mathrm{ml}\end{array}$ \\
\hline 1. & EGC & $204.2 \pm 4.2$ \\
\hline 2. & C & $9.4 \pm 0.4$ \\
\hline 3. & EC & $13.1 \pm 0.1$ \\
\hline 4. & EGCG & $240.8 \pm 3.6$ \\
\hline 5. & CAF & $103.6 \pm 1.8$ \\
\hline 6. & ECG & $67.8 \pm 1.4$ \\
\hline
\end{tabular}

Tab. 1 lists the retention time of flavan-3-olii which is a subgroup of flavonoids, which include catechins. Leaves green tea catechins contain six majorities: $(+)$-catechin $(\mathrm{C})$, (-)-epicatechin (EC), (+)-galocatechina, (-)-epicatechin gallate (ECG), (-)-gallate (EGC) and (-) -epigallocatechin gallate (EGCG) and contain also the caffeic acid.

Compared with the study done in 2009 by Rugină O. Dumitrița at an another product that exist in the romanian market (Vedda) it is note that in our samples the EGC has a higher value in comparation with $0.86 \pm 0.11$, as well as $\mathrm{C} 4.28 \pm 0.02$, EC $3.43 \pm 0.02$, EGCG $1.95 \pm 0.04$, ECG $0.21 \pm 0.05(\mathrm{mg} / \mathrm{g})$. In our sample the EGCG can be found in the greatest amount. However the study undertaken by Reto M. et al., 2007 showed a considerable variability in catechins content. The levels of epigallocatechin gallate (EGCG) ranged from 117 to $442 \mathrm{mg} / \mathrm{l}$, epicatechin 3-gallate (EGC) from 203 to $471 \mathrm{mg} / \mathrm{l}$, epigallocatechin (ECG) from 16.9 to $150 \mathrm{mg} / \mathrm{l}$, epicatechin (EC) from 25 to $81 \mathrm{mg} / \mathrm{l}$ and catechin (C) from 9.03 to 115 $\mathrm{mg} / \mathrm{l}$. Caffeine contents in the green tea infusions studied were between 141-338 mg/l. Another study made by Vodnar D. and Socaciu Carmen, 2012 showed the following concentrations: EGC $7.13 \mathrm{mg} / \mathrm{ml}$, C $1.59 \mathrm{mg} / \mathrm{ml}$, EC $3.34 \mathrm{mg} / \mathrm{ml}$, EGCG $53.18 \mathrm{mg} / \mathrm{ml}$, CAF 19.16, ECG $3.29 \mathrm{mg} / \mathrm{ml}$. These results were expressed in the same unit of measure as this study and it has been observed that the samples from this study indicate much higher values. This is due to the fact that the extract used in this work has a higher concentration, $2 \%$.

II. Fruit and vegetable labels formulation

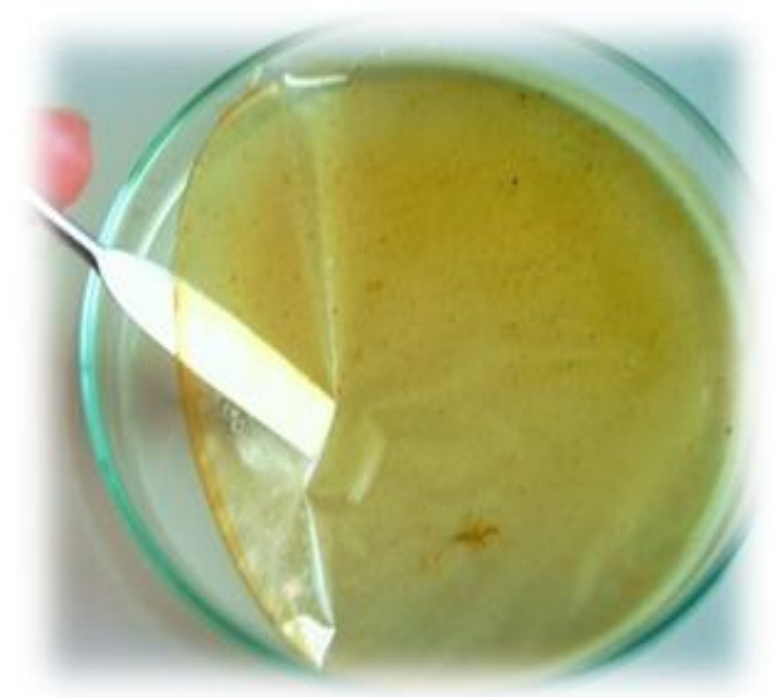

Fig. 3. Label made of chitosan with green tea extract 
III. Antimicrobial potential of biodegradable labels

Trial A:

The antimicrobial effect quantified by the total number of germs $\left(\mathrm{ucf} / \mathrm{cm}^{2}\right)$

Tab. 2

\begin{tabular}{|l|c|c|c|}
\hline Product & Initial number (Unwashed) & Washed & $\begin{array}{c}\text { Bioactive labels with: } \\
\text { Chitosan+Green tea }\end{array}$ \\
\hline Pepper & 1200 & 250 & 0 \\
\hline Tomato & 50 & 15 & 1 \\
\hline Apple & 96 & 7 & 3 \\
\hline Nectarine & 1000 & 500 & 99 \\
\hline
\end{tabular}

Trial B:

The antimicrobial effect quantified by the total number of germs $\left(\mathrm{ucf} / \mathrm{cm}^{2}\right)$

Tab. 3

\begin{tabular}{|l|c|c|c|}
\hline Product & Initial number (Unwashed) & Washed & $\begin{array}{c}\text { Bioactive labels with: } \\
\text { Chitosan+Green tea }\end{array}$ \\
\hline Pepper & 1000 & 665 & 320 \\
\hline Tomato & 281 & 225 & 102 \\
\hline Apple & 650 & 380 & 340 \\
\hline Nectarine & 1309 & 994 & 132 \\
\hline
\end{tabular}

In terms of antimicrobial activity we can say the following:

In the first trial on the basis of determinations made (NTG), the four products analyzed (pepper, tomato, apple, and nectarine) shows the following: tomato.

Pepper has the highest initial microbial load, followed by nectarine, apple and

After the washing usual at tap was indicated a slight decrease in the number of germs to all the products made in the analysis. Fruits and vegetables which have applied label showed a considerable decrease in the total number of germs.

Tag that contains chitosan and green tea has proved effective in all samples, in particular pepper, it has been found that the absence of micro-organisms on the surface after washing with it; at tomato were found $1 \mathrm{ucf} / \mathrm{cm}^{2}$, at apple $3 \mathrm{ucf} / \mathrm{cm}^{2}$ and at nectarine 99 ucf $/ \mathrm{cm}^{2}$ (Tab. 2).

The second trial was performed on the same samples with the same labels.

As a first interpretation at this products was found a high amount of bacteria due to their origin, being purchased on the market place with increased availability growth of microorganisms.

Nectarine had the highest microbial load, followed by pepper, apple and tomato. The highest efficacy labels appear to be on the nectarine, which has been a considerable decrease, followed by pepper, tomato and apple (Tab. 3).

The labels have proved to have a good impact, and this is due to the fact that it acts against microorganisms by the chitosan with bioactive compounds from green tea. 
The antimicrobial activity can be attributed to the study done by Kumar A. et al., 2012, and the study made by Hamilton-Miller J. M. T., 1995 who tested the antibacterial activity at three different extract of green tea. All the extracts were tested for antibacterial activity by disc diffusion method. Antibacterial assay was performed at $10 \mu 1,20 \mu 1$, and $30 \mu 1$ concentrations. Significant antibacterial activity was reported for all extracts with results. Aqueous extracts has shown antibacterial activity against six bacteria isolated.

The bactericidal activity of this labels can also be made due the chitosan, which has been observed in numerous studies its ability against microorganisms. It was used in a study even extend the valability of some vegetables products (Dong H. et al., 2004).

Liu H. et al., 2004 showed the effect of chitosan acetate solution against Escherichia coli and Staphylococcus aureus by the enumeration of viable organisms at different incubation times and demonstred that the damage was likely caused by the electrostatic interaction between $\mathrm{NH}_{3}{ }^{+}$groups of chitosan acetate and phosphoryl groups of phospholipid components of cell membranes.

The antimicrobial activity of the labels can be assumed to prove the effectiveness of the interaction of polymer with anionic groups on the microbial cell surface, thus causing a waterproof layer that prevents transport of essential substances, chitosan is a policationic.A second mechanism involved is inhibition of protein synthesis micro RNA and valid consideration based on the study conducted by Liu F. X. et al., 2001. Other way the antimicrobian action of the labels can be assumed to be that they inhibit microbial growth in that act as chelating agents, retaining metals, trace elements and essential nutrients for microbial growth (Roller and Covill, 1999).

IV. Reducing potential of pesticides from the surface of fruits and vegetables

Tab. 4

Retention times for the active substances according to the figures below

\begin{tabular}{|l|c|}
\hline \multicolumn{1}{|c|}{ Active substance } & Retention time \\
\hline Mefenoxan -fungicide & 14,661 \\
\hline Tiametoxam-insecticide & 23,495 \\
\hline
\end{tabular}

Tab. 5

The influence of the label on the pesticide residues in the surface of the products

\begin{tabular}{|l|l|l|l|l|l|l|l|l|}
\hline \multirow{2}{*}{ Pesticide } & \multicolumn{2}{|c|}{ Tomato } & \multicolumn{3}{l|}{ Nectarine } & \multicolumn{2}{l|}{ Apple } & \multicolumn{2}{l|}{ Pepper } \\
\cline { 2 - 9 } & Before & After & Before & After & Before & After & Before & After \\
\hline Mefenoxan & & & $96 \mathrm{ppm}$ & $85 \mathrm{ppm}$ & $87 \mathrm{ppm}$ & $71 \mathrm{ppm}$ & & \\
\hline Tiametoxam & $18.6 \mathrm{ppm}$ & $17.5 \mathrm{ppm}$ & & & & & $25 \mathrm{ppm}$ & $19 \mathrm{ppm}$ \\
\hline
\end{tabular}

For each pesticide taken into consideration was injected different concentration (standard). Based on the resulting areas establish a standard curve, which is determined by the values (Tab. 5).

Potential skin decontaminant of fresh fruit and vegetables was supposed to be achieved by chelation of these compounds by using polymers (chitosan) (Roller and Covill, 1999). 


\section{CONCLUSION}

Assuming that the labels made have a decontamination action at the surface of fresh fruits and vegetables, as respects microbial and pesticide residues, the results were positive, and the hypothesis was satisfied. In this paper, were made biodegradable labels with chitosan and green tea extract, which incorporates into the polymer matrix, bioactive natural compounds. In the first part of the study were practically identify bioactive compounds from green tea, which are responsable for reducing the microbial load. Based on these considerations, it was determined the antimicrobial potential of the label and the label has proved effective at all the samples. The peppers have indicated a reduction of up to $100 \%$ in the first trial. In terms of pesticide residues results were also effective.

Acknowledgments. This study was supported and encouraged by University of Agricultural Sciences and Veterinary Medicine, Cluj-Napoca.

\section{REFERENCES}

1. Alschuler L (1998). Green Tea: Healing tonic. Am J Natur Med, 5, 28-31.

2. Apostu S.( 2009). Microbiologia produselor alimentare, Vol II, Ed. Risoprint, Cluj-Napoca, p. 243-252.

3. Apostu S., Ancuța M. Rotar (2009). Microbiologia produselor alimentare. Lucrări practice, Vol.III, Ed. Risoprint, Cluj-Napoca, 189-191.

4. Devgan K. (2012). Why fruit, vegetable peels are good for you. Hindustan Times, New Delhi 1-2.

5. Dong H., Cheng L., Tan J., Zheng K., Jiang Y. (2004). Effects of chitosan coating on quality and shelf life of peeled litchi fruit. J. Of Food Engineering, 64(3), China, 355-358.

6. Graham N. H.., (1992) Green tea composition, consumption, and polyphenol chemistry. Preventive medicine 21(3), USA, 334-350.

7. Hamilton-Miller J. M. T. (1995). Antimicrobial properties of tea (Camellia sinesis L.). Antimicrobial Agents and Chemotherapy, 39(11), United Kingtom, 2375-2377.

8. Keikothaile B.M., P. Spanoghe, W.Steurbaut (2010). Pesticide Residues in fruits and vegetables. Food and Chemical Toxicology 48(1), Belgium, 244-249.

9. Kim K-Y., Oh J-Y, Chung O-J, Lee J-S, Kim O-K (2009). Chemical composition of green tea according to processing methods and extraction conditions. Food Sci. Biotechnol. 18(5), Korea, 1212-1217.

10. Krol, W.J., Arsenault T.L., Pyplypiw, H.M., Mattina M.J.I. (2000). Reduction of pesticide residues on produce by rinsing. J.Agric. Food Chem. 48, New Haven, 4666-4670.

11. Kumar A., Kumar A., Thakur P., Patil S., Payal C., Kumar A. (2012). Antibacterial activity of green tea (Camellia sinesis) extracts against various bacteria isolated from environmental sources. Recent Research in Science and Technology 4(1), India, 9-23.

12. Liu F. X., Guan L. Y., Yang Z. D., Li Z., Yao D. K. (2001). Antibacterial action of chitosan and carboxymethylated chitosan. J. Of Applied Polymer Science. 79, 1324-1335.

13. Liu H., Du Y., Wang X., Sun L., (2004). Chitosan kills bacteria through cell membrane damage. Int. J. Of Food Microbiology 95(2), China, 147-155.

14. Lu C. Li, Wang I. C., Sye F. W. (2010). Applications of chitosan beads and porous crab shell powder for the removal of 17 organochlorine pesticides (OCPs) in water solution. Carbohydrate Polymers 83(4), Taiwan, 1984-1986.

15. Reto M., Figueira E. M., Filipe M. H., Almeida M. M. C. ( 2007), Chemical Composition of Green Tea (Camellia sinensis) Infusions Commercialized in Portugal. Plant Foods for Human Nutrition 62(4), Portugal 139-144.

16. Roller S., N. Covill (1999). The antifungal properties of chitosan in laboratory media and apple juice. International 47(1-2), London, UK, 67-77. 
17. Rugină O.Dumitrița (2009). Caracterizarea unor extracte vegetale bogate în flavan-3-oli cu potențial antioxidant și apoptotic. Rezumatul tezei de doctorat, Cluj-Napoca, 11.

18. Vodnar C. D., Socaciu Carmen (2012). Green tea increases the survival yield of Bifidobacteria in simulated gastrointestinal environment and during refrigerated conditions. Chemistry Central Journal 6(61), Cluj-Napoca, 2-3.

19. Zaferi T. N. (2006). Green tea and its polyphenolic catechins: Medicinal uses in cancer and noncancer applicatios. Life Science 78, USA, 2073-2080.

20. Zander A. and Bunning M. (2010). Guide to Washing Fresh Produce. Food and Nutrition Series/ Food Safety 9.380, Colorado, 1-2. 